\title{
Koordinasi Pengembangan Kawasan Kota Lama Semarang Dalam Kaitannya Dengan Pengembangan Pariwisata
}

\section{Djoko Nugroho Witjaksono}

Keywords: old city, heritage, planning, cultural resource management, conservation, colonial

\section{How to Cite:}

Witjaksono, D. N. Koordinasi Pengembangan Kawasan Kota Lama Semarang Dalam Kaitannya Dengan Pengembangan Pariwisata. Berkala Arkeologi, 15(3), 193-198. https:// doi.org/10.30883/jba.v15i3.694

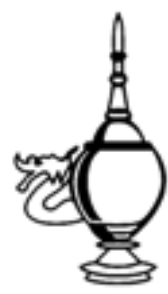

\section{Berkala Arkeologi}

https:/ / berkalaarkeologi.kemdikbud.go.id/

Volume 15 No. 3, 1995, 193-198

DOI: $10.30883 /$ jba.v15i3.694

\section{(†)}

This work is licensed under a Creative Commons Attribution-NonCommercialShareAlike 4.0 International License. 


\title{
KOORDINASI PENGEMBANGAN KAWASAN KOTA LAMA SEMARANG DALAM KAITANNYA DENGAN PENGEMBANGAN PARIWISATA
}

\author{
Djoko Nugroho Witjaksono \\ (Bidang Muskala Kanwil. Depdikbud Jawa Tengah)
}

\section{Visi Masa Depan Kota}

1 Kota sebagai wadah kehidupan warga kotal masyarakat kota perlu memiliki kenyamanan sebagai tempat bermukim.

2. Kota sebagai proses kehidupan dan pengambilan keputusan memerlukan keruntutan gambaran dari masa lalu, masa sekarang, dan masa depan kotanya.

3. Kota yang mampu menghadirkan tapak pertumbuhan kotanya akan selalu potensial untuk menjadi kota yang nyaman ditinggali dan dikunjungi.

4. Proses pembangunan kota yang baik akan menghadirkan tipe pembangunan baru, pembangunan peremajaan dan pembangunan pemugaran (konservasi) secara tepat pada berbagai bagian kotanya.

\section{II.Gambaran Umum Kawasan Kota Lama Sema-rang \\ Kota Semarang mempunyai letak paling unik} di Jawa, Venesia dari Timur, julukan orang Belanda yang pernah tinggal lama di kota ini. Dae-rah pesisir yang dikelilingi perbukitan menghijau. Terletak pada ketinggian bukit, sehingga dapat leluasa menikmati pemandangan kota bagian bawah sampai lepas pantai.

Posisi geografisnya cukup strategis dengan alamnya yang cantik. Hal tersebut menarik perhatian orang Belanda sehingga mengembangkan kota ini. Kota yang terdiri dari dua wilayah atas dan bawah dirancang sedemikian rupa. Wilayah bagian bawah dirancang sebagai kawasan perdagangan, sedangkan bagian atas digunakan untuk kawasan hunian dan peristirahatan.

Melalui perjalanan sejarah panjang, Semarang memiliki potensi bangunan kuna warisan Negeri Belanda tersebut. Gedung-gedung berukuran besar dengan pilar-pilar serta jendela-jendela besar penuh detail ornamen kolonial masih dapat dijumpai di berbagai sudut kota.

Salah satu kawasan historis di Semarang terletak di seputar Kota Lama yang populer dengan sebutan Little Netherlands. Di kawasan ini dapat disaksikan puluhan gedung tua dengan berbagai bentuk arsitektur barat yang dibangun sekitar abad XIX-XX, satu gedung diantaranya didirikan sebelum masa itu. Gedung tersebut merupakan bangunan tertua dan menjadi ciri khas
Kota Lama yaitu Gereja Blenduk. Gereja berarsitektur kubah berfasade ini dibangun tahun 1753 pada masa pendeta Johanes Wilhelmus Swemmelaar.

Kawasan Kota Lama dahulu merupakan kawasan pemukiman Belanda dilengkapi dengan fasilitas sosial penunjang. Saat ini ruang-ruang yang ada sebagian masih dipergunakan seper: fungsi sebelumnya tetapi banyak pula yang tioak dipergunakan sebagaimana mestinya, seperti digunakan gudang/bengkel. Penggunaan ruang pada kawasan seluas 31,25 ha sekarang untuk pemukiman, fasilitas sosial, pertokoan, ruang terbuka, perkantoran, industri, Jasa perbankan dan pergudangan.

\section{Permasalahan}

1. Bagaimana bentuk dan tipologi struktur Kota Lama?.

2. Bagaimana arah kecenderungan pertumbuhan kawasan ini?.

3. Bagaimana pengembangan kawasan ini dalam kaitannya dengan pemanfaatan pariwisata?

\section{Bentuk Struktur Kawasan Kota Lama}

Bentuk struktur kawasan Kota Lama pada dasarnya dapat dilihat dari sisi fisik dan sisi nonfisik.

\section{A. Sisi Fisik}

Bentuk ini mencakup penggambaran yang jelas secara visual dari suatu struktur kawasan Dalam hal ini kerangka penataan kawasan Kota Lama dibentuk oleh Jalan Let.Jend. Soeprapto karena jalan ini membentuk sumbu yang diben-tuk oleh Jalan Suari.

Kawasan Kota Lama merupakan perpaduan antara unsur solid dan void. Unsur solid merupakan suatu elemen yang bersifat masif seperti bangunan-bangunan yang berfungsi sebagai wadah aktivitas manusia. Unsur solid cenderung bersifat private domain memberikan suatu kehadiran massa dan volume objek pada Jalan dan tapak.

Unsur void merupakan ruang terbuka dalam lingkup suatu kawasan yang peranan keberadaannya ditentukan oleh bangunan-bangunan yang melingkupinya. Unsur void dibedakan menjadi dua yaitu: 


\section{Internal void}

Yaitu ruang terbuka dalam lingkup suatu bangunan dan bersifat private domain. Kualitas intemal void dapat dipengaruhi oleh konfigurasi bangunan serta keunikan fasade-fasade interior bangunan yang melingkupinya. Bangunan kawasan Kota Lama yang memiliki internal void antara lain: Gereja Gedangan, Kompleks Yayasan Marsudirini dan Kanisius (Jl. Ronggowarsito); Hotel Jansen, Kantor Satlantas, Gedung PT Kerta Niaga, Gedung Bank Exim, Gedung Panca Niaga, Gedung PT Asuransi Jiwasraya (Jl. Let.Jend. Soeprapto), Gedung Bank Bumidaya (Jl. Kepodang)

\section{External Void}

Yaitu ruang terbuka di luar lingkup suatu ba. ngunan. Kualitas ruang yang ditimbulkan dipengaruhi oleh fasade bangunan yang melingkupinya. Bangunan di kawasan Kota Lama yang memiliki external void adalah PT Asuransi Jiwasraya dan Gereja Blenduk (JI. Let.Jend. Soeprapto)

Peranan sosial ruang terbuka dipengaruhi elemen-elemen fisik arsitektur yang dapat dikategorikan dua sudut pandang, yaitu: private domain (lihat keterangan IV.A.1) dan public domain berupa taman PT. Asuransi Jiwasraya, taman di depan POM bensin JI. Ronggawarsito, taman Gereja Blenduk dan lapangan depan Stasiun Tawang.

\section{B. Sisi Konseptual (nonfisik)}

Bentuk struktur ini mencakup non visual atau bersifat konsepsi dan simbolis. Dari kon-sepstual terdapat dua macam bentuk meliputi:

1. Sumbu-sumbu konsepsual

Kawasan Kota Lama terdapat pada Jalan Suari vertikal dan Jalan Let Jend. Soeprapto sebagai sumbu horizontal dengan Gereja Blenduk sebagai pusat sumbu (titik potong sumbu tersebut). Karena itulah sentra aktivitas kawasan Kota Lama terletak di area Gereja Blenduk.

2. Hubungan konseptual antara eleman kota Adanya hubungan aktivitas di daerah Stasiun Tawang, terminal angkutan umum Johar dan daerah sekitar taman POM bensin Jalan Ronggowarsito.

\section{Tipologi Bentuk Kawasan Kota Lama}

Pola Kota Lama cenderung menggabung-kan pola kota Barat dengan budaya daerah yang dihuni. Hal tersebut mengacu pada kepadatan penduduk, tata guna lahan, ruang terbuka, ide-ide arsitektur, dan estetis yang hidup. Tipologinya mengacu pada bentuk perkembangan kota yang berpola kawasan konsentris dengan titik pusat aktivitas dan arus pergerakan di area Gereja Blenduk.

\section{Arah Kecenderungan Perkembangan}

Arus pergerakan aktivitas kawasan Kota Lama berlangsung pada ruas Jalan Ronggowarsito, Let Jend Soeprapto, Mpu Tantular, dan Jalan Merak yang menunjukkari adanya suatu pola pergerakan aktivitas dan sekaligus sebagai pusat pertumbuhan (Jl. Mpu Tantular, Kawasan Jumatan, Jl. Let Jend Soeprapto, dan JI. Kepodang).

Struktur kota yang konsentris memberikan pilihan pengembangan kawasan ini. Pilihan ini merupakan arah yang dapat dikembangkan dari karakter suatu pusat arus pergerakan dan sekaligus akan menghidupkan struktur Kota Lama dan memperluas jaringan pergerakan (sektor Jl. Let.Jend Soeprapto, sektor Jl. Kepodang, Jl. Merak, dan Jl. Ronggowarsito).

\section{Prospek Pengembangan Pariwisata}

Kawasan Kota Lama dengan berbagai potensinya sebagai Little Netheriands apabila dikembangkan secara optimal akan merupakan aset budaya yang sangat menguntungkan, baik dari segi pelestarian, pendidikan, ilmu penge-tahuan, maupun kepariwisataan yang memiliki efek ganda terhadap perkembangan daerah. Satu sisi memberikan manfaat ekonomi secara opti-mal, sisi lain memungkinkan tumbuhnya apresia-si dan pemahaman sejarah perkembangan Kota Semarang.

Dalam rangka pengembangan kepariwisataan di Jawa Tengah umumnya dan Semarang khususnya, maka pengembangan dan pemanfaatan kawasan Kota Lama sebagai aset budaya mutlak diperlukan. Terlebih wisatawan mancanegara untuk datang lebih banyak lagi ke Jawa Tengah. Dengan demikian pengembangan dan pemanfaatan kawasan Kota Lama sebagai daya tarik wisata Semarang akan membantu pengembangan pariwisata di Jawa Tengah khususnya dan indonesia umumnya.

Upaya mengembangkan kawasan Kota Lama sebagai salah satu objek dan daya tarik unggulan di Jawa Tengah, mutlak diperlukan keterpaduan dan kematangan perencanaannya. Tahapan rencana pengembangan yang perlu dilakukan antara lain.

1. Studi setting, yaitu penelitian yang dapat memberikan gambaran mengenai kehidupan manusia dan lingkungannya pada masa itu

2. Studi kelayakan kawasan wisata, yaitu suatu penelitian yạng dapat memberikan rekomendasi terhadap kemungkinan pengembangan kawasan Kota Lama sebagai kawasan wisata, rencana penyediaan fasilitas penunjang dan rencana pelestarian lingkungan. 
3. Studi pengembangan pariwisata, yaitu suatu penelitian yang memberikan arahan dan alternatif kegiatan kepariwisataan meliputi rencana pengembangan atraksi wisata, rencana penyediaan fasilitas penunjang dan rencana pelestarian lingkungan.

4. Studi perencanaan teknis, pengelolaan dan perkiraan sumber dana, yaitu suatu penelitian yang memberikan arahan pembangunan fisik (pembangunan pemugaran) kawasan Kota Lama, bentuk pengelolaan, dan sumber dana pembiayaannya

5. Tahapan pelaksanaan.

\section{Koordinasi Pengembangan Kawasan Kota Lama}

Untuk mewujudkan kawasan Kota Lama sebagai kawasan wisata diperlukan suatu penanganan serius secara multidisipliner, terarah dan dilakukan skala besar dalam penanganan penelitian, pelestarian, pengamanan kawasan, dan pemanfaatan - pengembangan kepariwisataan.

Segi penelitian pihak Balai Arkeologi Yogyakarta dapat diperhitungkan keterlibatannya bekerjasama dengan Persatuan Sarjana Arsitektur Indonesia (PSAI). DPU Cipta Karya, Universitas dan instansi penelitian lainnya baik dari dalam maupun luar negeri.

Segi pelestarian dan pengamanan kawasan. perlu diadakan koordinasi antara pihak Depdikbud baik di tingkat pusat (Direktorat Linbinjarah) maupun di tingkat daerah (Kanwil Depdikbud Prop. Jawa Tengah, Kantor Depdikbud Kodia Semarang, serta Suaka Peninggalan Sejarah dan Purbakala). Koordinasi ini juga harus melibatkan Pemerintah Daerah Tingkat I dan II, masyarakat sekitar dan para pemakai gedung-gedung di kawasan Kota Lama agar tidak terjadi lagi kegiatan pengrusakan yang tidak bertanggungjawab. Untuk itu kebijaksanaan pembangunan yang berorientasi "win-win solution" (pendekatan kompromistis) dapat menjadi pilihan yang diminati. Pemilik tanah/bangunan bersejarah yang dikonservasi dapat mengoptimalkan tanah/bangunannya secara finansial sementara tapak sejarah di atas tanah/bangunannya terjaga dan lestari. Perlu juga ditingkatkan pelayanan kepada masyarakat yang akan memugar bangunannya (renovasi, rehabilitasi, restorasi) dan mengkaitkannya dalam pro-ses pemberian izin membangun (IBM) termasuk juga pemberian insentif atau bonus yang me-madai agar tapak sejarah pertumbuhan kota da-pat terjaga dan lestari.

Dalam hal pengembangan kepariwisataan, perlu diadakan koordinasi antar Dinas Pariwisata Tingkat I Jawa Tengah dan Tingkat II Kodia Se- marang, Bappeda Tingkat I dan II, Kanwil Depdikbud Prop. Jawa Tengah dan Kantor Depdikbud Kodia Semarang, para penanam modal, para travel biro, dan lain-lain.

\section{Penutup}

Pembangunan pemugaran kota merupakan tipe pembangunan baru bagi kota-kota kita dan harus dapat berdampingan dengan tipe pembangunan lainnya yang telah ada sebelumnya. Sementara itu, saat ini sedang mencari bentuk yang sesuai untuk suasana pembangunan yang ada. Gerakan pembangunan dipengaruhi kekuatan ekonomi besar dan berorientasi mencari keuntungan saja. Untuk itu perlu dicarikan kebijaksanaan pembangunan yang tepat ("win-win solution") dan pemberian intensif atau bonus yang memadai agar tiap sejarah pertumbuhan kota dapat terjaga dan lestari.

Komunikasi dengan berbagai pihak yang berkecimpung dalam pembangunan pemugaran kawasan Kota Lama dan rencana pengembangan kepariwisataannya semakin terasa diperlukan agar gerakan cinta tapak sejarah dapat mengimbas kepada masyarakat warga kota lainnya

\section{KEPUSTAKAAN}

Anonim,1993. Pola Umum Kebijaksanaan Pengembangan Pariwisata Jawa Tengah. Semarang:Dinas Pariwisata Jawa

Anonim,1993.Inventarisasi Data Masalah Urban Design Kawasan Kota Lama Kodia Semarang (Final Report). Semarang:DPU Cipta Karya.

Anonim,tt Konsevasi Agar Gerakan Cinta Tanah Air. Bangunan dan Lingkungan Kotamadya Dati II Semarang. Semarang Bappeda Kotamadya Dati II Semarang

Gunawan Permadi.1995.Kota Lama, Nuansa Kekayaan Jiwa. Suara Merdeka, 20 Januari, him.III

Muhammad Noor Chamil.1993. Little Nethertands di Tengah Gemuruh Kota Semarang. Majalah Asri No.122, tanggal 1.31 Mei

Wisnu,M.Ardjo, Ir.tt. Pengalaman Pembangunan Pemugaran Bagian Kota yang Bersejarah di DKI Jakarta. Tidak diterbitkan 


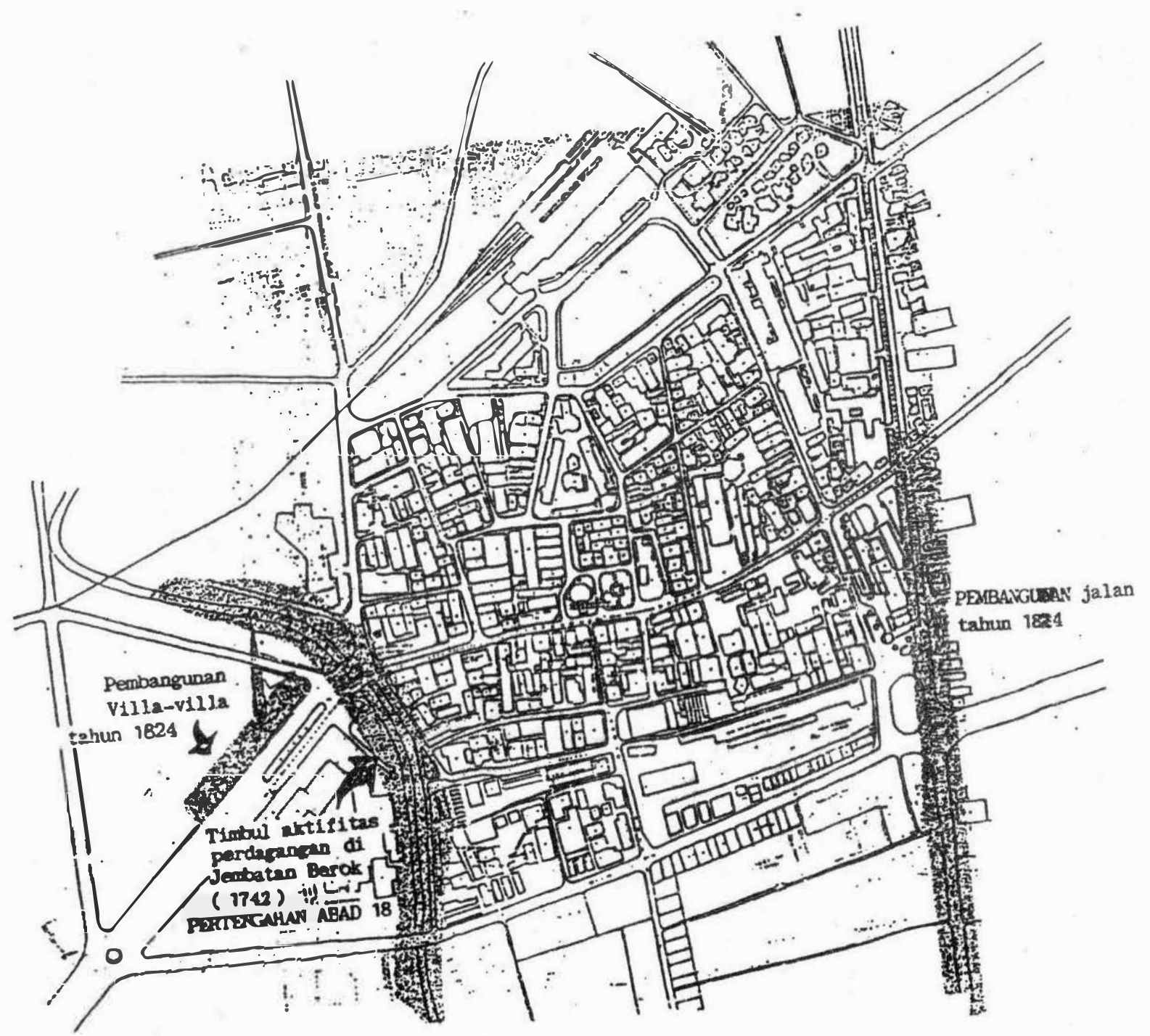

PERTENGAHAN ABAD 18

BERKE:MBANGNYA AKT'IFITAS PELABUHAN YANG TUMBUH DI SEPANJANG KALI SEMARANG SAMPAI KAWASAN PECINAN (GANG PINGGIR) YANG DIIKUTI PULA DENGAN TIMBULNYA DENGAN AKTIFITAS TAHUN 1824 PEMERINTAH KOLONIAL BEI.ANDA MEMUTUSKAN UNTUK MEMBONGKAR DINDING PENJAGAAN/BENTENG YANG MENGELILINGI KOTA LAMA.

TERJADI PENGEMBANGAN KOTA LAMA

PEMBANGUNAN VILLA-VILLA DI BOJONG DAN RANDUSARI

- PEMBANGUNAN JALAN-JALAN BARU : JL. BOJONG, JL. RANDUSARI DAN Ul. MATARAM.

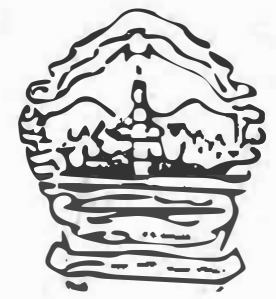

PIIMERINTAII PROP. DATI I JATENG DINAS PIKEERJAAN UMUM CIPTA KARYA

INVENTARISASI DATA

RANCANGAN KOTA

UNTUK KOTA LAMA

\section{GAMBBAR}

PERTUMBUHAN KOTA LAMA PADA

PERTENGAHAN ABAD XVIII \& XIX

DIKAITKAN DENGAN KONDISI

MASA KINI

\begin{tabular}{|l|}
\hline KETERANCIAN \\
\hline PE. PEREMBANGAN AKTIFITAS \\
\hline SAMIBAR NO : \\
\hline SKAI.A \\
\hline UTARA \\
\hline
\end{tabular}




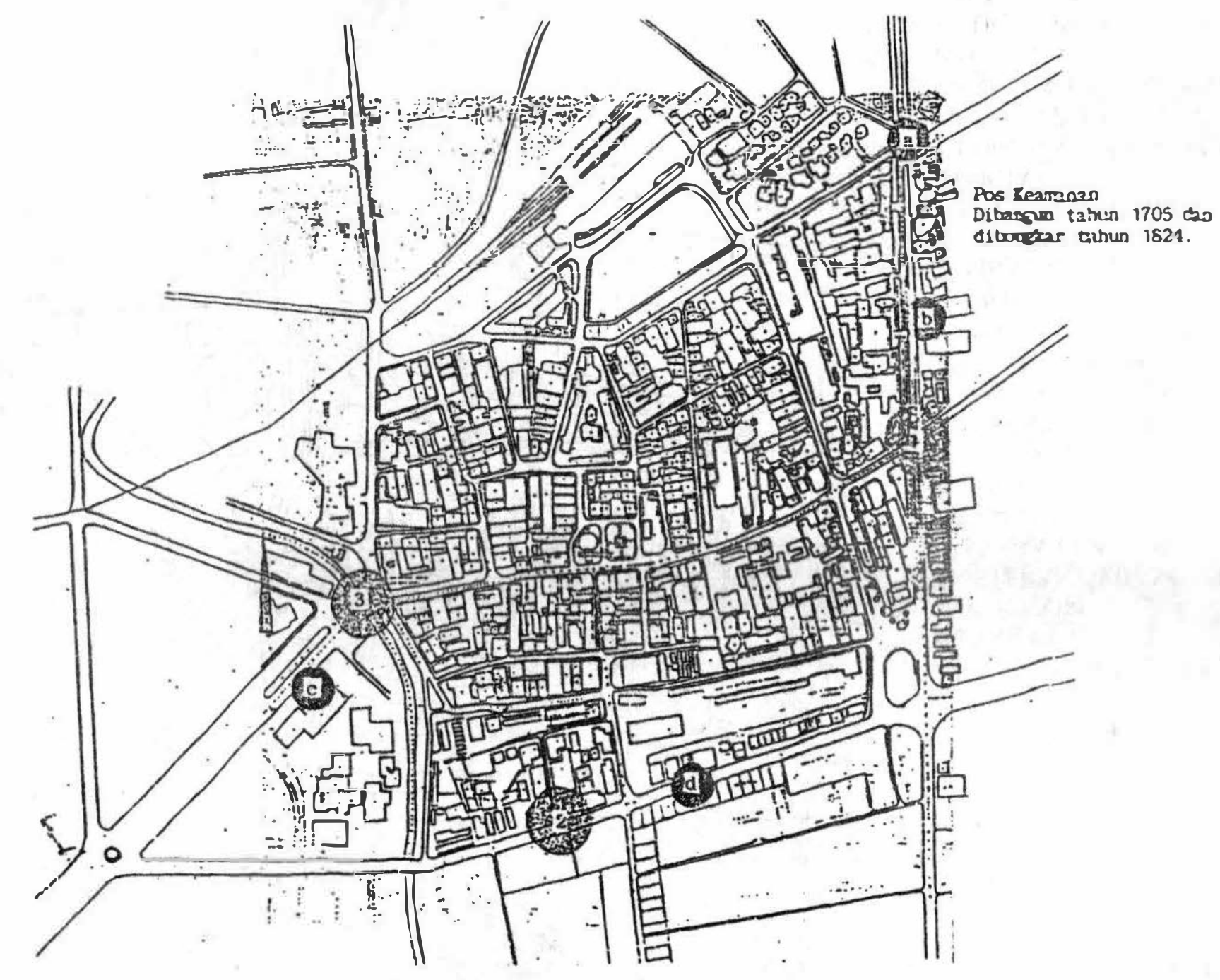

SEJAK BERKUASANYY VOC, SEMARANG MENJADI SEBUAH KOTA BENTENG Y YANC; DILI:NGIKAPI DFNGAN TIGA BUAAH PINTU GERBANG DAN POS-POS KEAMANAN OI KOTA LAMA

KAWASAN KOTA LAMA BERKEMBANG PESAT MENJADI KAWASAÑ PEMUKIMAN IJAN PUISAT PEMLRIN. TAHAN.

PEMERINTAH KOLONIAL BELANDA, SEIRING DENGAN MENINGKANYA PERAN PENTING KAII SEMARANG YANG MERUPAKAN JALUR TRANSPORTASI PEREKONOMIAN ITAMA.

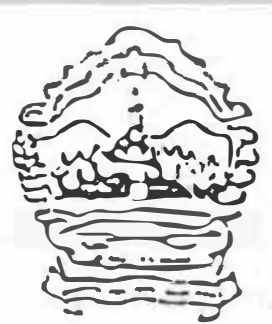

PEEMERINIAH P'ROP. DATI I IATI:NG; IINAS PI:KLRJAANUMUM CIPIA KARYA

INVENTARISASI I)ATA

RANCANGSAN KOTA

UNTUK KOTA LAMA

\section{(iAMHAR}

SUPER IMPOSSED AWAL,

KESEJARAHIAN KOTA I.AMA

DIKAITKAN DENGIAN MASA KINI KI:IRKANCINN

\section{שx}

करो

1. DE GOSTER PORT ( Pintu Gerbang Timur)

2 DE ZUNDER ( Pintu (ierbang Selatan)

3. DE WESTER / GEVERNEMENT SPOORT ( Pintu Grerbang Barat )

7 (Pos Keamanan).

a. DE HERSTELER

b. CEYLON

c. DE LIER

d. AMSTERDAM

( $\triangle A N B$ AR NO)

iKAl.

UARA 


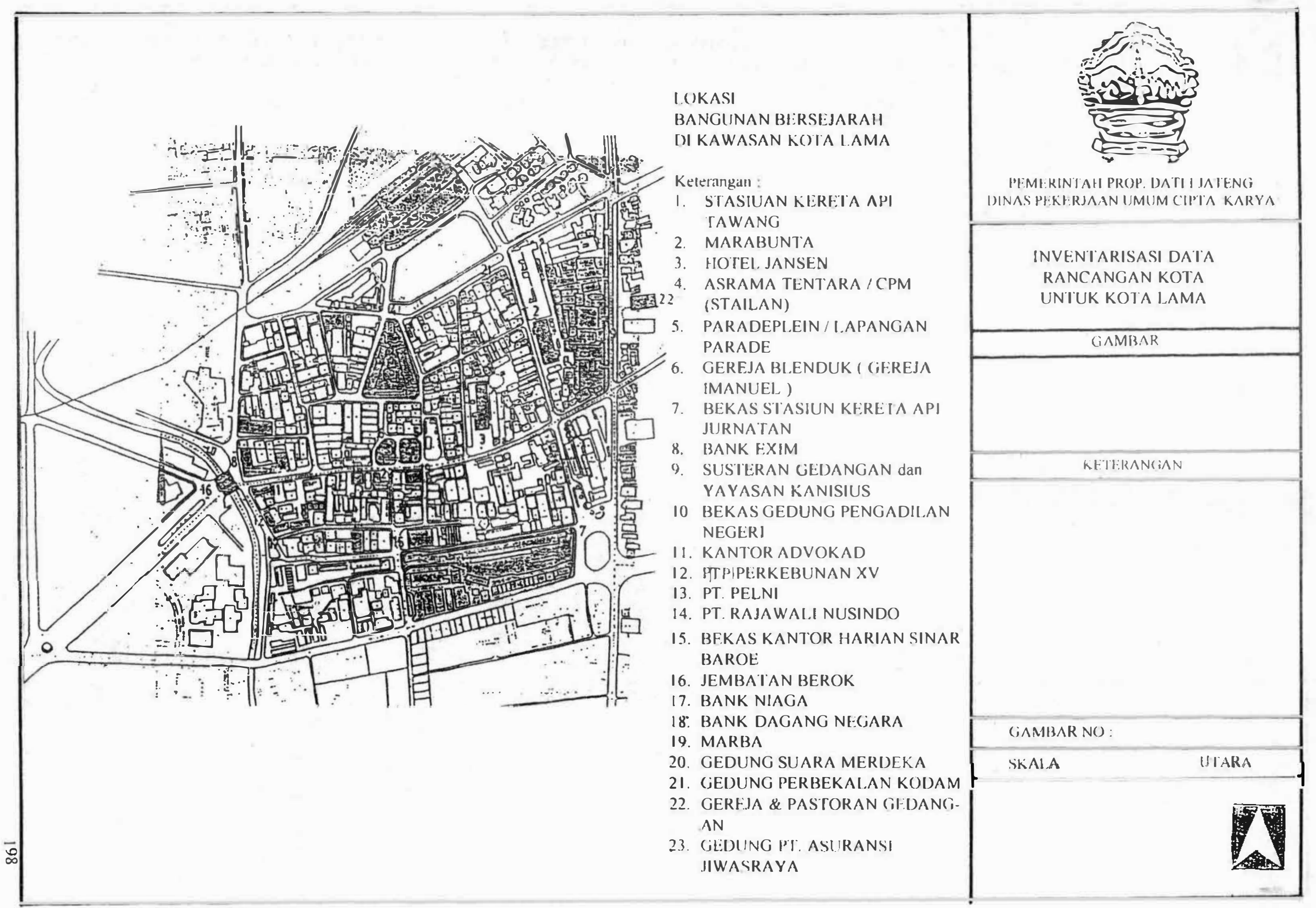

